\title{
Potential benefits of increased application of water to paddy fields in Taiwan
}

\author{
Yu-Chuan Chang, ${ }^{1}$ Chun-E. Kan, ${ }^{1}$ Gwo-Fong Lin, ${ }^{2 *}$ Chao-Lin Chiu ${ }^{3}$ and Yuan-Chuan Lee ${ }^{1}$ \\ ${ }^{1}$ Department of Agricultural Engineering, National Taiwan University, Taipei 10617, Taiwan \\ ${ }^{2}$ Department of Civil Engineering, National Taiwan University, Taipei 10617, Taiwan \\ ${ }^{3}$ Department of Civil and Environmental Engineering, University of Pittsburgh, Pittsburgh, PA 15261, USA
}

\begin{abstract}
:
The potential benefits of increased application of water to paddy fields in Taiwan are investigated in this paper. A conceptual model is used to represent the hydrological system of the paddy field. A technique is presented to estimate the parameters of the model. Field experiments also are performed for parameter estimation and model verification. The simulated results are in good agreement with the observed during model verification. With parameters estimated from the field data, the model is used to simulate the effects of applying water beyond current practice. The simulation results show that the downward percolation increases when the irrigation water increases. However, the percolation reaches a capacity rate no matter how large the amount of water applied. This phenomenon results from the existence of a hard layer below the paddy field. The effects of raising the height of levees around paddy fields are also studied. Copyright $@ 2001$ John Wiley \& Sons, Ltd.
\end{abstract}

KEY WORDS irrigation; paddy field; hydrological system; water budget; parameter estimation

\section{INTRODUCTION}

Rainfall in Taiwan is abundant but has a very uneven time distribution. About $75 \%$ of average annual rainfall occurs during May and October. Such a climatic factor coupled with the steep island topography necessitates effective flood control in wet months and conservation and efficient use of water in dry months (Kuo, 1994). In agriculture the main crop is rice. The rice production in paddy fields requires so much water that it is under constant pressure to conserve water. Therefore, the traditional concept is to apply only the minimum amount of water required for the growth of rice, and to use the most efficient irrigation method that minimizes the evaporation, percolation and runoff from the paddy fields (Chu, 1992).

During the past 30-40 years the rapid industrialization, economic growth and rise in living standards has resulted in a dramatic increase in water demands by the domestic and industrial water users. This imposes an additional pressure to the agricultural sector, presently using about $80 \%$ of available water resources in Taiwan, to sharply curtail the water use. Furthermore, under the current prospect of Taiwan becoming a member of the World Trade Organization (WTO), which will surely allow foreign countries to increase importing rice of lower cost or higher quality, a substantial reduction in paddy field acreage in Taiwan is imminent. Under such an environment, some of the concepts that were unconceivable before begin to appear logical and worth exploring. For example, a concept that now seems logical is to apply some of the excess water that will become available owing to the reduced rice field acreage to some of the remaining paddy fields (Lee et al., 1995), under the following hypotheses.

\footnotetext{
* Correspondence to: Professor G.-F. Lin, Department of Civil Engineering, National Taiwan University, Taipei 10617, Taiwan. E-mail: gflin@ce.ntu.edu.tw
} 
1. The increased application of water to the rice plants may improve the productivity and rice quality. For instance, the required average depth in paddy fields in Taiwan is $6 \mathrm{~cm}$, but it is as much as $22 \mathrm{~cm}$ in Japan. The difference seems to explain the fact that Japan's rice output ranks among the top in the world (Kan et al., 1997).

2. To apply more water, the height of the levees around the paddy fields must be raised, which in turn will make the paddy fields become effective rainwater cistern systems during wet months (Hayase, 1994).

3. The increased water depth in paddy fields will increase percolation of water through soil and hence increase the recharging of ground-water aquifers (Wen, 1995).

4. The elevated ground-water table and increased runoff from paddy fields that will result from the increased application of water will benefit the plant growth and the overall ecological system of the adjacent areas (Sekiya, 1992).

Against the above background, the purpose of this paper is to present results from a project to investigate the potential benefits of an increased application of water to paddy fields.

\section{FIELD EXPERIMENT AND DATA}

The experimental area, located in the district under the jurisdiction of the Kaohsiung Irrigation Association, is approximately 22 ha. The irrigation water is diverted from Laonong Creek, where about $80 \%$ of average annual rainfall occurs between May and October. The soil of the paddy field is sandy loam. Because of the good conditions of irrigation channels, the conveyance loss is assumed to be negligible. During the experiments, the water depth in the paddy field was maintained at about $6 \mathrm{~cm}$ initially, but it was increased to range from 10 to $30 \mathrm{~cm}$ in the mid-season.

A rain gauge and a US Weather Bureau Class A Land Pan were installed to record the rainfall and evaporation, respectively. The evapotranspiration was estimated using the crop coefficients recommended by FAO (Doorenbos, 1977). Standard $90^{\circ} \mathrm{V}$-notch weirs were placed to measure the irrigation water and drainage discharge. The water depth in the paddy field was maintained with earth levees, the height of which had been raised to $30 \mathrm{~cm}$. Measuring sticks were installed at the corner of paddy fields to record the water depth $D(t)$. Figure 1 shows the rainfall $R(t)$, evapotranspiration $E_{\mathrm{T}}(t)$, irrigation water $W(t)$ and drainage discharge $Q(t)$ observed during 1-18 August 1999. Figure 2 shows the time variation of the water depth in the paddy field during the experimental period.

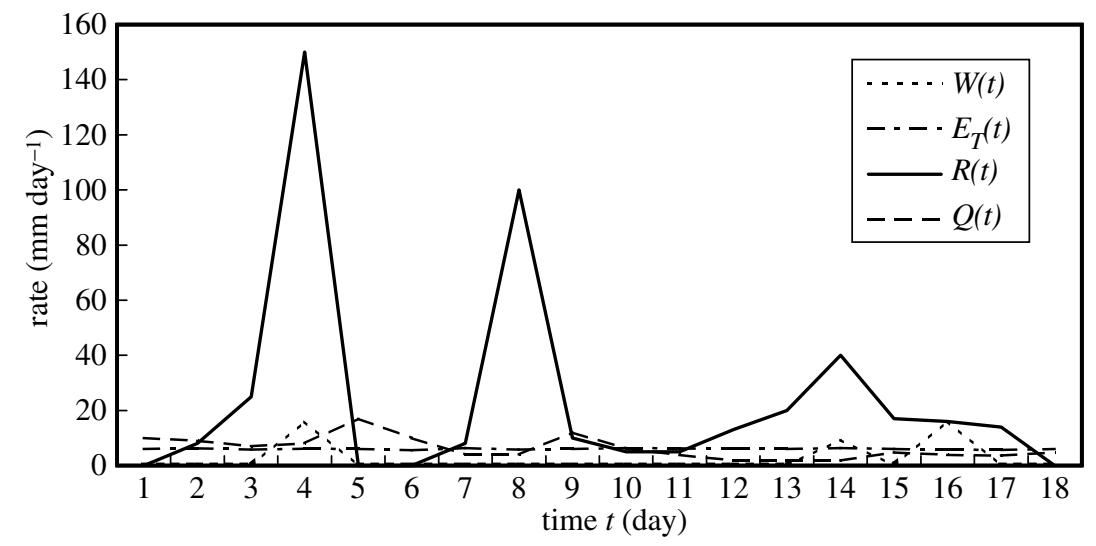

Figure 1. The observed rainfall, evapotranspiration, irrigation water and drainage discharge during 1-18 August 1999 


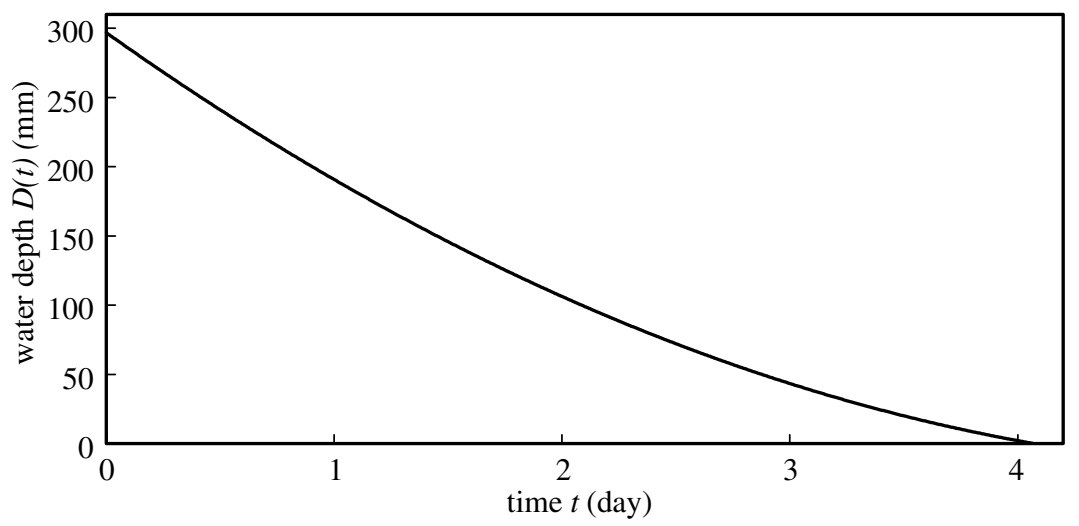

Figure 2. The observed water depth in the paddy field

\section{MATHEMATICAL MODEL}

Figure 3 describes the water budget of a paddy field system (Watanabe, 1999), in which $E_{\mathrm{T}}(t)$ is the evapotranspiration rate at time $t, D(t)$ is the water depth in the paddy field, $B$ is the elevation of the paddy field above the ground-water table, $P(t)$ is the rate of downward percolation, $S p(t)$ is the seepage rate through the levee to the drainage channel, $R(t)$ is the rainfall rate, and $W(t)$ is the rate of irrigation water applied.

A mathematical model that can be used to represent the system shown in Figure 3 and simulate the effects of applying water beyond the current practice is the conceptual 'tank model' (Sugawara, 1972). The tank model is widely used in Japan and Taiwan for the simulations of watershed runoff. In this paper the concept of the tank model is adopted and applied to the paddy field system, which is considered as a cascade of $I$ tanks. The model is illustrated in Figure 4.

In Figure $4, i$ is the index corresponding to the tank $(i=1,2, \ldots, I), j$ is the index corresponding to the pipe on a tank $(j=1,2, \ldots, J), t$ is the index corresponding to the time (day) $(0<t \leq T), I$ is the total number of tanks, $J$ is the total number of pipes on a tank, $T$ is the total duration (days), $H_{\mathrm{L}}$ is the height of the first tank (mm), $H(i, j)$ is the elevation of pipe $j$ on tank $i(\mathrm{~mm}), h(i, t)$ is the water level in tank $i$ at time $t(\mathrm{~mm}), W(t)$ is the rate of irrigation water applied at time $t\left(\mathrm{~mm} \mathrm{day}^{-1}\right), R(t)$ is the rainfall rate at time $t\left(\mathrm{~mm} \mathrm{day}^{-1}\right), E_{\mathrm{T}}(t)$ is the evapotranspiration rate at $t\left(\mathrm{~mm} \mathrm{day}^{-1}\right), G(i, t)$ is the vertical discharge rate on tank $i$ at time $t\left(\mathrm{~mm} \mathrm{day}^{-1}\right), F(i, t)$ is the horizontal discharge rate on tank $i$ at time $t\left(\mathrm{~mm} \mathrm{day}^{-1}\right)$, and $Y(t)$ is the total simulated drainage discharge rate at $t\left(\mathrm{~mm} \mathrm{day}^{-1}\right)$. Table I gives the physical meanings of the tank model parameters.

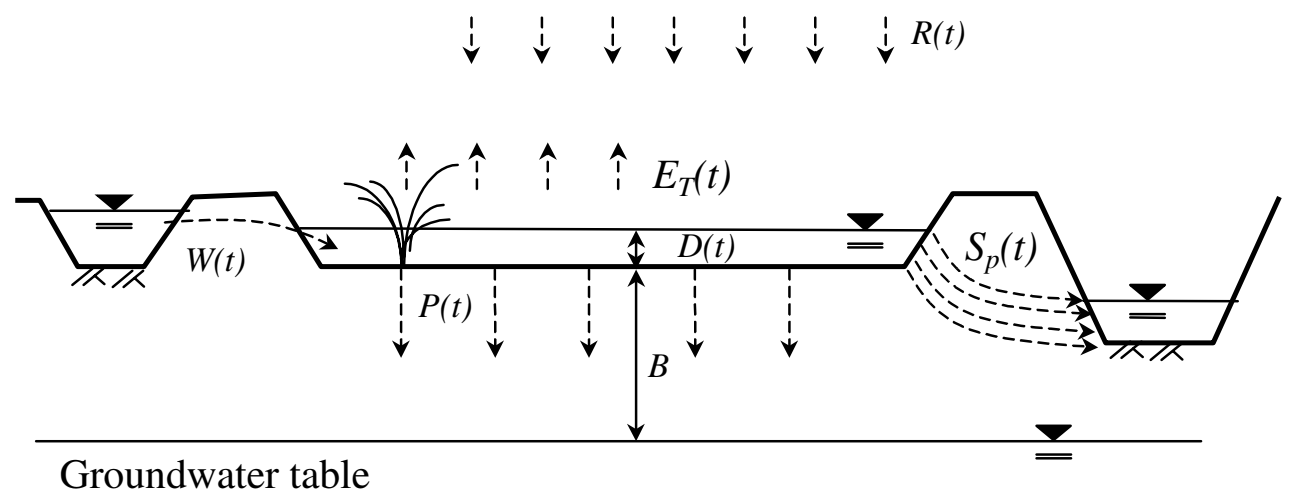

Figure 3. Hydrological system of the paddy field 


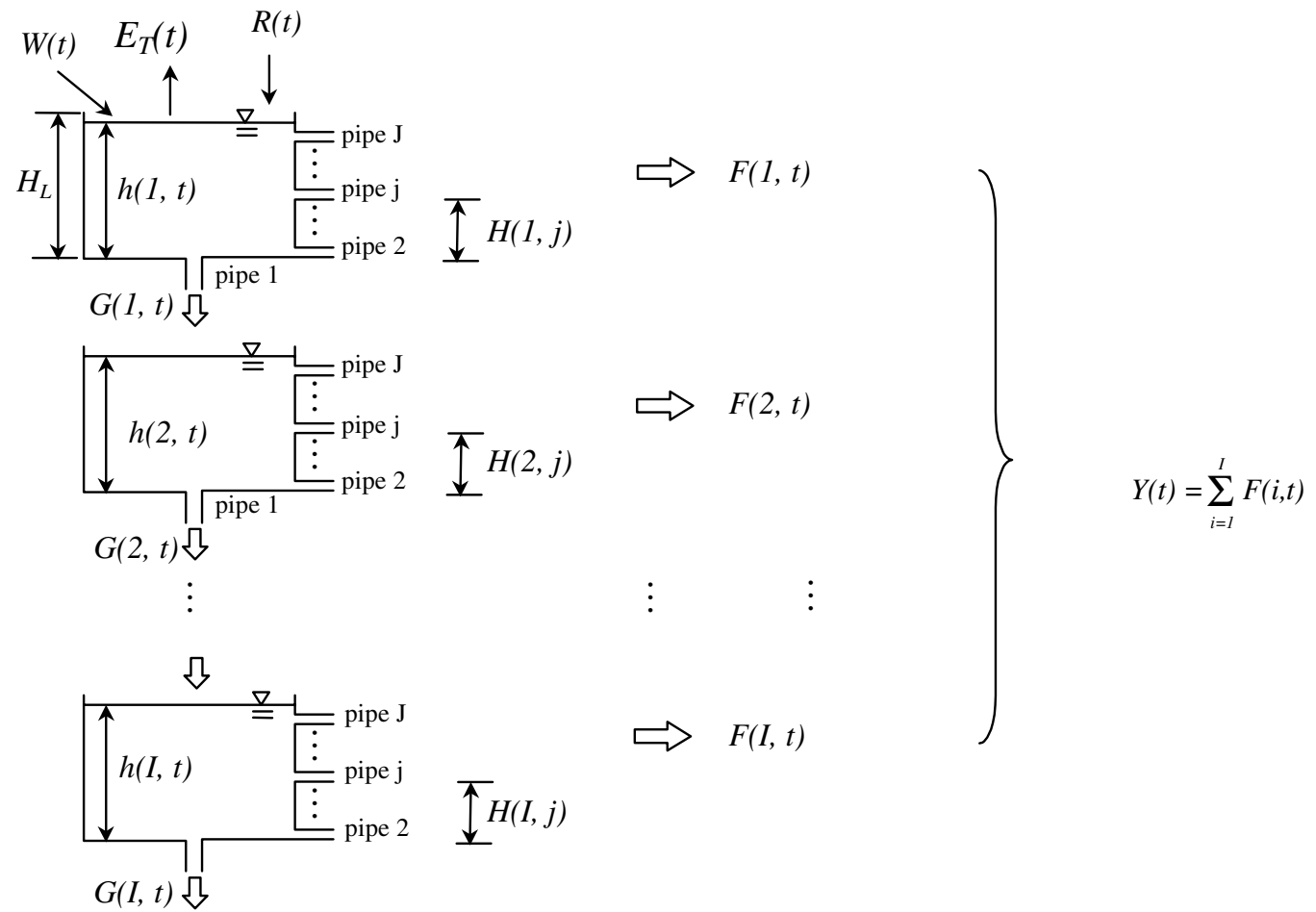

Figure 4. Illustration of the tank model

Table I. The physical meanings of the tank model parameters

\begin{tabular}{ll}
\hline Parameter & \multicolumn{1}{c}{ Physical meaning } \\
\hline$H_{\mathrm{L}}$ & Height of the paddy field's levee \\
$C(i, j)$ & Coefficient corresponding to the movement of water at different depths \\
$H(i, j)$ & Height of a soil layer \\
$h(i, t)$ & Piezometric head of a soil layer at different depths \\
$G(i, t)$ & Vertical discharge rate at different depths \\
$F(i, t)$ & Horizontal discharge rate at different depths \\
$Y(t)$ & Discharge of drainage channel in paddy field \\
$W(t)$ & Discharge of irrigation channel in paddy field \\
$R(t)$ & Rainfall \\
$E_{\mathrm{T}}(t)$ & Evapotranspiration rate of paddy field \\
\hline
\end{tabular}

The terms $F(i, t)$ and $G(i, t)$ in Figure 4 can be expressed as

$$
\begin{aligned}
& F(i, t)=\left\{\begin{array}{lr}
{\left[\sum_{j=2}^{J} C(i, j)\right][h(i, t)-H(i, j)]+h(1, t)-H_{\mathrm{L}}} & \text { for } i=1 \text { and } h(1, t)>H_{\mathrm{L}} \\
{\left[\sum_{j=2}^{J} C(i, j)\right][h(i, t)-H(i, j)]} & \text { for } h(1, t) \leq H_{\mathrm{L}}
\end{array}\right. \\
& G(i, t)=C(i, 1) h(i, t)
\end{aligned}
$$

where $C(i, j)$ is the coefficient of pipe $j$ on tank $i\left(\right.$ day $\left.^{-1}\right)$. 


\section{ESTIMATION OF MODEL PARAMETERS}

\section{Non-linear programming}

The model parameters, $C(i, j), i=1,2, \ldots, I, j=1,2, \ldots, J$ can be solved using optimization techniques. The problem herein can be formulated as

$$
\operatorname{minimize} Z=\sum_{t=1}^{T}\left[1-\frac{Y(t)}{Q(t)}\right]^{2}
$$

subject to

$$
\begin{aligned}
Y(t) & =\sum_{i=1}^{I} F(i, t) \\
h(i, t+1) & = \begin{cases}h(1, t)+W(t+1)+R(t+1)-F(1, t)-E_{\mathrm{T}}(t+1)-G(1, t) \text { for } i=1 \\
h(i, t)+G[(i-1), t]-F(i, t)-G(i, t) & \text { for } i=2,3, \ldots, I\end{cases} \\
h(1, t) & =H_{\mathrm{L}} \text { when } h(1, t) \geq H_{\mathrm{L}} \\
h(i, t)-H(i, j) & =0 \text { when } h(i, t) \leq 0 \\
0 & \leq \sum_{j=1}^{J} C(i, j) \leq 1
\end{aligned}
$$

Once the parameters of the model are obtained, we can then simulate $G(i, t)$ and $Y(t)$ to find out the potential benefit of increased application of water $W(t)$ to paddy fields. Owing to the large number of parameters involved in the non-linear programming, it is not easy to find the optimal combination of parameters. Hence the method described below is proposed to determine the parameters associated with the first tank. Once the parameters of the first tank are found, the remaining parameters are determined using the non-linear programming, which can be solved by the steepest descend method (Wang, 1991).

\section{Estimation of parameters of the first tank}

During the period of no irrigation and no rainfall, i.e. $W(t)$ and $R(t)$ equal to zero, the water budget equation for the paddy field system of Figure 3 can be written as

$$
-\frac{\mathrm{d}[A D(t)]}{\mathrm{d} t}=S p(t)+A P(t)+A E_{\mathrm{T}}(t)
$$

in which $A$ is the area of the paddy field $\left(\mathrm{m}^{2}\right)$, and

$$
S p(t)=n L D(t)
$$

in which $n$ is a coefficient depending on the width of the levee $\left(\mathrm{m} \mathrm{day}^{-1}\right)$ and $L$ is the length of a levee through which seepage takes place $(\mathrm{m})$.

Equation (9) can be written further as

$$
-\frac{\mathrm{d}[A D(t)]}{\mathrm{d} t}=n L D(t)+A K_{a} \frac{D(t)+B}{L_{a}}+A E_{\mathrm{T}}(t)
$$

in which $K_{a}$ is the coefficient of permeability $\left(\mathrm{m} \mathrm{day}^{-1}\right)$, and $L_{a}$ is the average length of downward percolation (m). Solution of (11) gives

$$
D(t)=[D(0)+M(t)] \exp (-t N)-M(t)
$$


in which $D(0)$ is the initial water depth in the paddy field (m)

$$
M(t)=\left[E_{\mathrm{T}}(t)+\left(B K_{a}\right) / L_{a}\right] / N
$$

and

$$
N=(n L) / A+K_{a} / L_{a}
$$

Under the same condition, i.e. $W(t)$ and $R(t)$ equal to zero, the total outflow from the first tank (see Figure 4) can be expressed as

$$
\begin{aligned}
-\frac{\mathrm{d} h(1, t)}{\mathrm{d} t} & =G(1, t)+F(1, t)+E_{\mathrm{T}}(t) \\
& =C(1,1) h(1, t)+\left[\sum_{j=2}^{J} C(1, j)\right][h(1, t)-H(1, j)]+E_{\mathrm{T}}(t) \\
& =\left[\sum_{j=1}^{J} C(1, j)\right] h(1, t)-\left[\sum_{j=2}^{J} C(1, j)\right] H(1, j)+E_{\mathrm{T}}(t) \\
& =\alpha h(1, t)+\alpha \beta
\end{aligned}
$$

in which

$$
\alpha=\sum_{j=1}^{J} C(1, j)
$$

and

$$
\beta(t)=\left\{\left[-\sum_{j=2}^{J} C(1, j)\right] H(1, j)+E_{\mathrm{T}}(t)\right\} / \alpha
$$

Integration of (15) gives

$$
h(1, t)=[h(1,0)+\beta(t)] \exp (-t \alpha)-\beta(t)
$$

A comparison of Equations (12) and (18) shows that these two equations are in the same form mathematically. The water level of the first tank $h(1, t)$ is equivalent to the water depth in the paddy field $D(t)$, i.e. $h(1, t)=D(t)$. Replacing $h(1, t)$ with $D(t)$ in Equation (15) and then differentiating both sides of (15) with respect to $D(t)$ gives

$$
\left.\frac{\mathrm{d}-\left[\frac{\mathrm{d} D(t)}{\mathrm{d} t}\right]}{\mathrm{d} D(t)}\right|_{D(t) \leq H_{\mathrm{L}}}=\alpha=\sum_{j=1}^{J} C(1, j)
$$

It can be seen from equation (15) that the model parameters $\{C(1, j), j=j, j+1, \ldots, J\}$ are redundant (i.e., of no contribution to $\mathrm{d} D(t) / \mathrm{d} t)$ when $D(t)<H(1, j)$. Hence, we can find $\{C(1, j), j=1,2, \ldots J\}$ according to

$$
C(1, j)=\left.\frac{\mathrm{d}-\left[\frac{\mathrm{d} D(t)}{\mathrm{d} t}\right]}{\mathrm{d} D(t)}\right|_{D(t)<H(1, j+1)}-\left.\frac{\mathrm{d}-\left[\frac{\mathrm{d} D(t)}{\mathrm{d} t}\right]}{\mathrm{d} D(t)}\right|_{D(t)<H(1, j)}=\sum_{j=1}^{j} C(1, j)-\sum_{j=1}^{j-1} C(1, j)
$$




\section{RESULTS AND DISCUSSIONS}

Based on the observed water depth in the paddy field $D(t)$, the parameters (i.e. pipe coefficients) of the first tank, $\{C(1, j), j=1,2, \ldots, J\}$, can be found according to the aforementioned method. Figure 5 shows that $C(1, j)$ decreases with increasing $H(1, j)$, the elevation of pipe $j$.

Once all the pipe coefficients of the first tank, $\{C(1, j), j=1,2, \ldots, J\}$, are determined, then the coefficients of pipes on the rest of the tanks can be determined using the aforementioned non-linear programming according to the observation of the water budget in the paddy field during the mid-season of paddy rice.

An excessive number of tanks will only increase the time needed for calculation and the improvement of the simulation results is limited. Hence, only cases with two and three tanks are considered herein. As the height of levees in the experimental field ranges from $105 \mathrm{~mm}$ to $125 \mathrm{~mm}$, three different heights of the first tank, namely, 105, 110 and $125 \mathrm{~mm}$, are considered. Table II presents the values of the objective function $Z$ for different combinations of the number of tanks and the height of the first tank. The objective function $Z$ achieves the minimum value when the number of tanks is two and the height of the first tank equals $125 \mathrm{~mm}$. The parameter values of tanks used in the simulations, namely, the elevations of pipes and the pipe coefficients, are presented in Table III. As shown in Table III, the pipe coefficients of the second tank are zero when the elevation of pipes is greater than $60 \mathrm{~mm}$. This means that the drainage discharge $Y(t)$ is mainly from the horizontal discharge of the first tank $F(1, t)$ (see Figure 4).

With the estimated parameters, the model is now ready for simulations. Figure 6 shows both the simulated and observed drainage discharge, $Q(t)$ and $Y(t)$, during the mid-season of paddy rice. The simulated drainage is in good agreement with the observed. The simulation also indicates that about $22 \%$ of the total water is discharged to the drainage channel, $42 \%$ percolates downward, and the remaining $36 \%$ accounts for evapotranspiration and variation of soil moisture content.

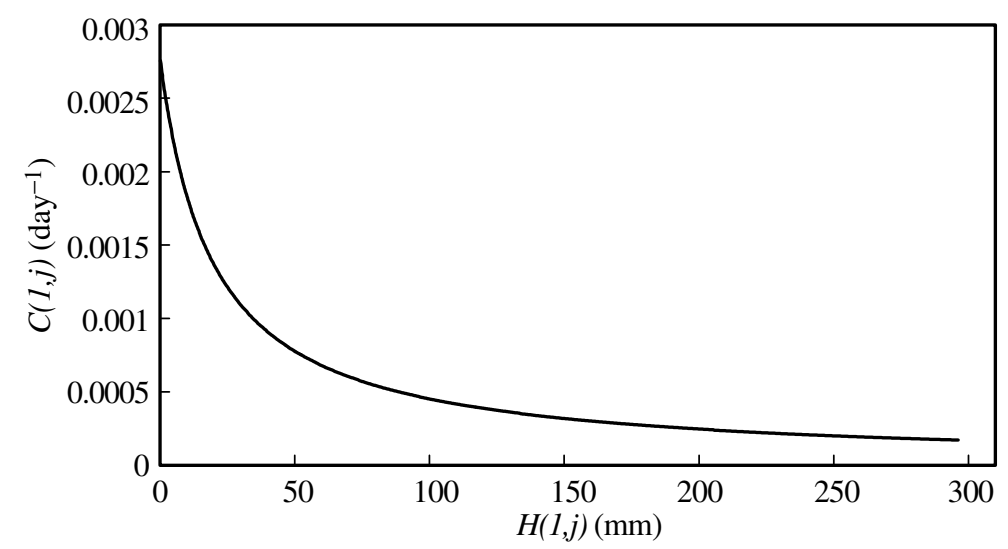

Figure 5. $C(1, j)$ versus $H(1, j)$

Table II. Values of objective function $Z$

\begin{tabular}{ccc}
\hline $\begin{array}{c}\text { The height of the first tank } \\
H_{\mathrm{L}}(\mathrm{mm})\end{array}$ & \multicolumn{2}{l}{ Value of objective function $Z$} \\
\cline { 2 - 3 } & Two tanks & Three tanks \\
\hline 125 & 3.608323 & 3.696254 \\
110 & 3.644202 & 28.24966 \\
105 & 3.666549 & 27.46689 \\
\hline
\end{tabular}


Table III. Parameter values of tanks used in the simulations

\begin{tabular}{rccc}
\hline Pipe $j$ & $\begin{array}{c}\text { Elevation of pipe } j \\
H(i, j)(\mathrm{mm})\end{array}$ & \multicolumn{2}{c}{ Pipe coefficient $C(i, j)$} \\
\cline { 3 - 4 } & & The first tank & The second tank \\
\hline 1 & 0 & $0 \cdot 521$ & $0 \cdot 612$ \\
2 & 0 & $0 \cdot 074$ & $0 \cdot 036$ \\
3 & 20 & $0 \cdot 001368$ & $0 \cdot 02$ \\
4 & 40 & $0 \cdot 000908$ & $0 \cdot 013$ \\
5 & 60 & $0 \cdot 000677$ & $0 \cdot 017$ \\
6 & 80 & $0 \cdot 000542$ & 0 \\
7 & 100 & $0 \cdot 000452$ & 0 \\
8 & 125 & $0 \cdot 000373$ & 0 \\
9 & 150 & $0 \cdot 000319$ & 0 \\
10 & 175 & $0 \cdot 000277$ & 0 \\
11 & 200 & $0 \cdot 000246$ & 0 \\
12 & 225 & $0 \cdot 00022$ & 0 \\
13 & 250 & $0 \cdot 0002$ & 0 \\
14 & 275 & $0 \cdot 000183$ & 0 \\
15 & 300 & $0 \cdot 000177$ & 0 \\
\hline
\end{tabular}

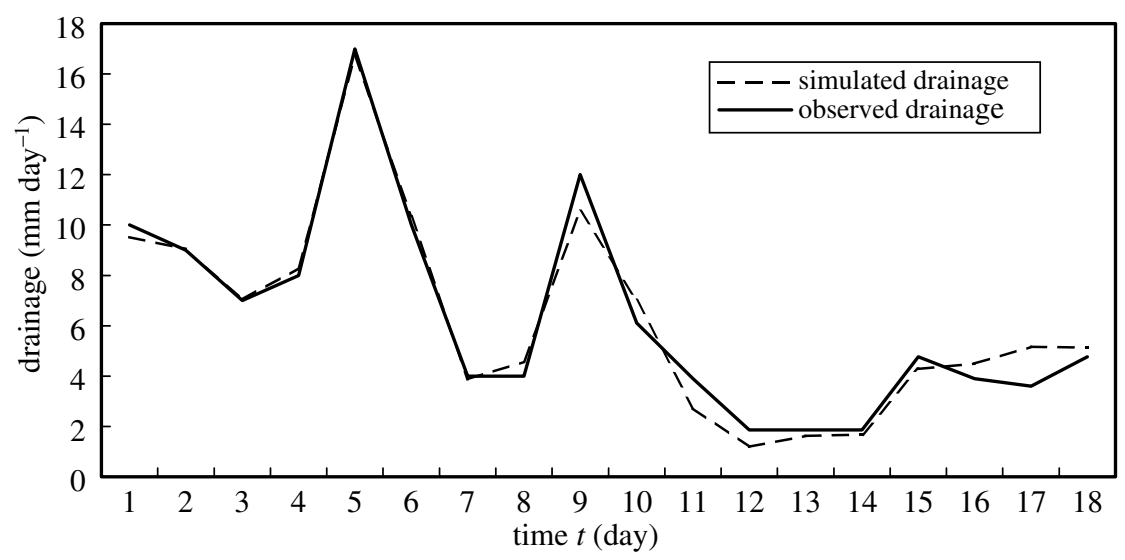

Figure 6. The simulated and observed drainage discharge during the paddy rice mid-season

To show the effects of levee height $H_{\mathrm{L}}$ on the paddy field hydrological system, different levee heights are considered. In the simulations, conditions other than levee height remain the same, and no irrigation water is applied to the paddy field. The results of simulated drainage $Y(t)$ for $H_{\mathrm{L}}=100,200,300,400$, 500 and $550 \mathrm{~mm}$ are presented in Figure 7. As shown in Figure 7, when the levee height increases, the peak rate and the volume of the drainage decrease and the time to peak delays. The decrease of drainage also implies an increase of downward percolation in the paddy field. Figure 8 shows the runoff coefficients for the rainfall-runoff events corresponding to different levee heights. The runoff coefficient decreases in general with increasing levee height. Simulations for $H_{\mathrm{L}}>550 \mathrm{~mm}$ are also performed. However, the curves for $H_{\mathrm{L}}>550 \mathrm{~mm}$ overlap that of $H_{\mathrm{L}}=550 \mathrm{~mm}$ in Figure 7. This means that under the given rainfall the drainage reaches a fixed rate no matter how large $H_{\mathrm{L}}$ is. This also explains why the runoff coefficient becomes a constant in Figure 8 when $H_{\mathrm{L}}>550 \mathrm{~mm}$.

Furthermore, to show the effect of the amount of irrigation water applied to the paddy field on the percolation, different irrigation water depths in the paddy field for which levee height $H_{\mathrm{L}}=350 \mathrm{~mm}$ are considered. The irrigation water is applied at $t=2,8$ and 15 days. Figure 9 presents the simulated percolation 


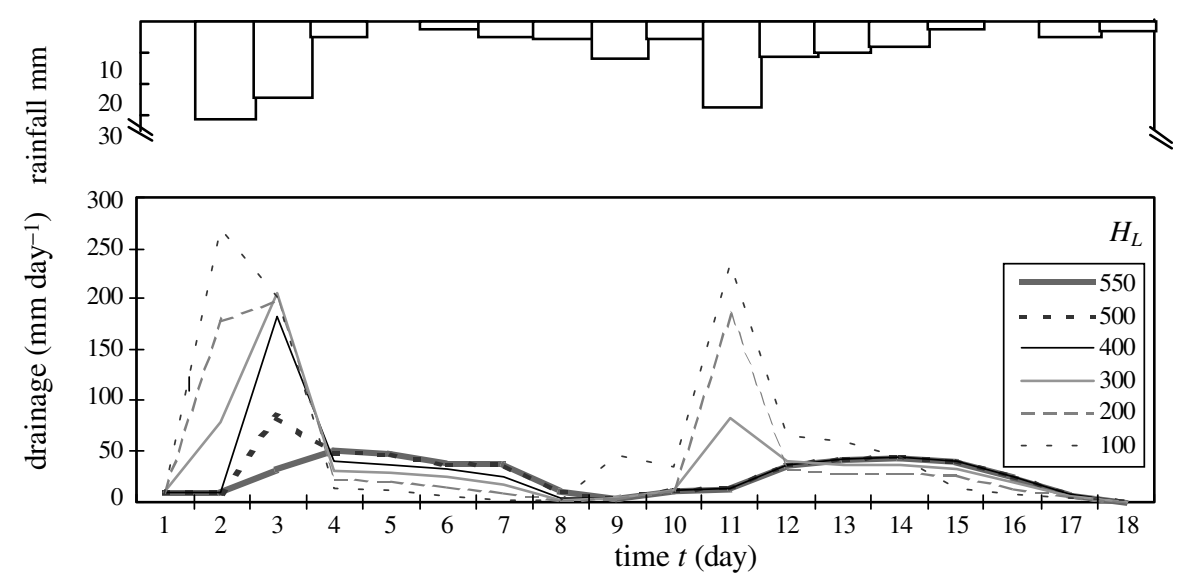

Figure 7. Effect of the height of the levee on drainage

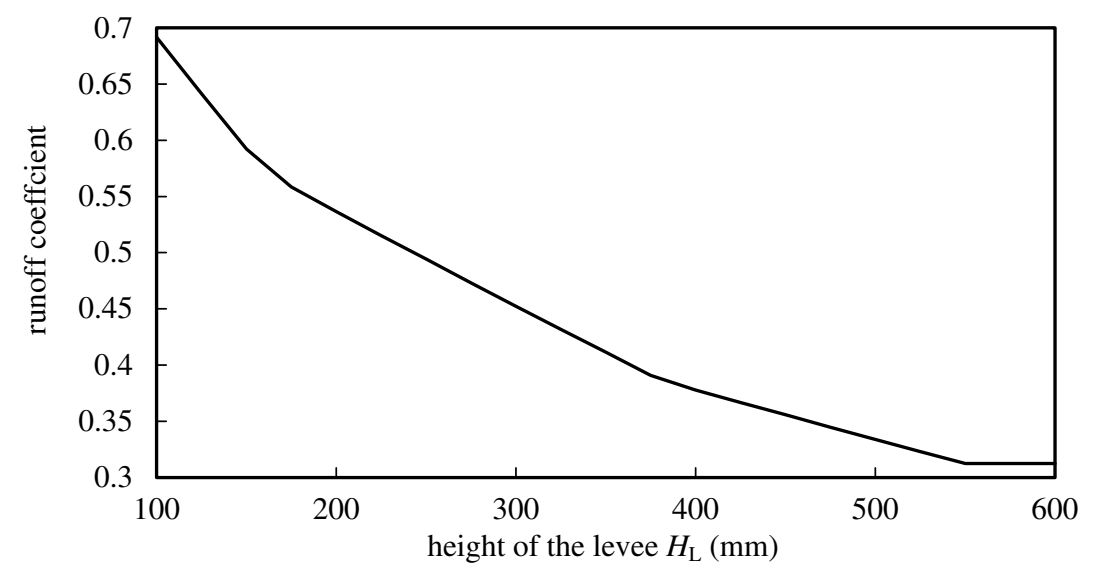

Figure 8. Runoff coefficient versus the height of the levee $H_{\mathrm{L}}$

for $W(t)=100,150,200,250,300$ and $350 \mathrm{~mm}$. Figure 9 indicates that the percolation $G(I, t)$ increases when the irrigation water depth $W(t)$ increases. The peak of percolation occurs two days after the application of irrigation. It should be noted that simulations for $W(t)>350 \mathrm{~mm}$ also have been performed. However, the curves for $W(t)>350 \mathrm{~mm}$ overlap that of $W(t)=350 \mathrm{~mm}$ in Figure 9. This means that percolation reaches a capacity rate no matter how large $W(t)$ is. The phenomenon results from the existence of a hard layer below the paddy field. The hard layer retards percolation in the paddy field. The hard layer can be found commonly in the paddy fields of Taiwan and Japan and is formed as a result of ploughing practice.

\section{SUMMARY AND CONCLUSIONS}

Irrigation water differs substantially from the water used in industrial or domestic consumption. Its purpose is to satisfy the evapotranspiration needs for maintaining the crop's normal growth. Thus, from the viewpoint of effective utilization of water resources, it is meaningless to save water during wet months. On the contrary, 


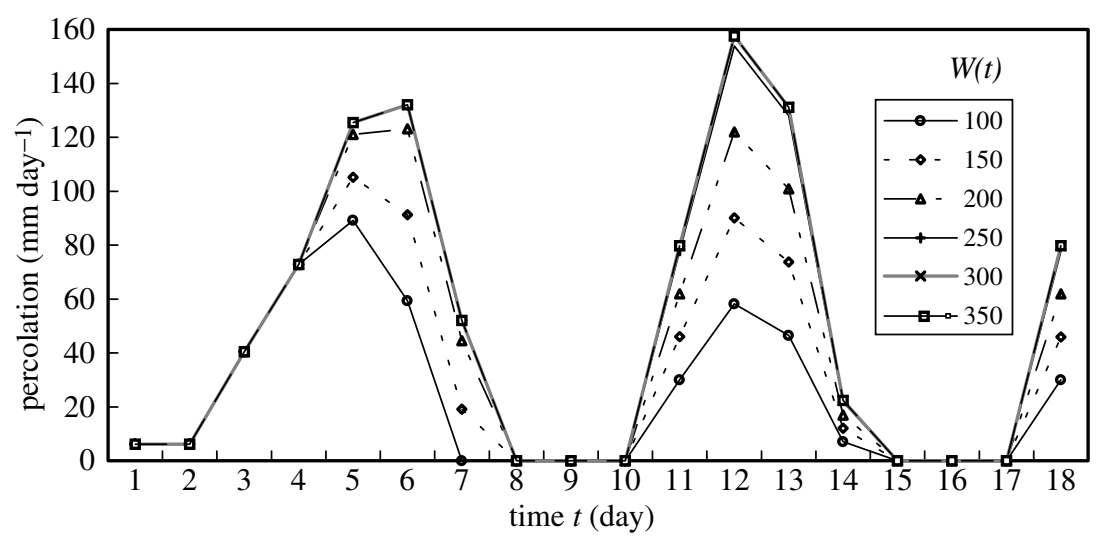

Figure 9. Effect of the amount of irrigation water applied to the paddy field on the percolation

if the excess water is available in rivers, it should be timely delivered to the paddy field to enhance the storage function of the paddy field, maintain adequate percolation and replenish ground-water, without having to follow the strict water conservation measures.

In this paper, the potential benefits of increased application of water to paddy fields in Taiwan are investigated through simulations. A conceptual hydrological model that regards the paddy field as a series of tanks is recommended for studying this problem. A technique is proposed for the estimation of model parameters. The model is verified to be useful for studying the water budget of the paddy fields. The effects of raising the height of levees around paddy fields and increasing the amount of irrigation water are presented respectively. In general, the drainage discharge decreases as the height of levees increases, and the percolation increases as the amount of irrigation water increases. However, the effect of increased application of water on percolation is constrained by the existence of a hard layer below the paddy field. The proposed method is expected to be useful for determining the height of levees and irrigation practice when increased application of water to paddy fields is desired.

\section{REFERENCES}

Chu JP. 1992. Study on saving water of irrigation in paddy rice field according to its ecology. Proceedings of the Workshop on Agricultural Water Management, Taipei, Taiwan; 91-103. (In Chinese.)

Doorenbos J. 1977. Guidelines for Predicting Crop Water Requirements. FAO Irrigation and Drainage Paper 24, Food and Agricultural Organization: Rome; 141 pp.

Hayase Y. 1994. Evaluation of paddy fields for flood control and a proposal of their enhancing project. Journal of the Japanese Society of Irrigation, Drainage and Reclamation Engineering 62(10): 943-948. (In Japanese.)

Kan CE, Chang YC, Chen KY. 1997. Sustainable agriculture land use: a preliminary strategy of paddy field irrigation for environmental, ecological and productive functions. Journal of Chinese Agricultural Engineering 43(1): 1-8. (In Chinese.)

Kuo CH. 1994. Irrigation in Taiwan. Proceedings of the Sino-Japanese Workshop on Agricultural Engineering, Taipei, Taiwan; 1-5. (In Chinese.)

Lee YC, Kan CE, Chang YC, 1995. A preliminary strategy of Taiwan water resources usage: a case study in Chia-Nan area. Journal of Taiwan Water Conservancy 43(3): 1-18. (In Chinese.)

Sekiya S. 1992. Functions of Paddy Fields. Ie No Hika Association: Tokyo; 644 pp. (In Japanese.)

Sugawara M. 1985. Methods of Runoff Analysis. Keo Litsu Book Co: Tokyo; 147 pp. (In Japanese.)

Wang Ru-Yih, Tan Tze-Hung 1991. Study on modified tank model and its application to the runoff prediction of a river basin. Journal of Taiwan Water Conservancy 39(3): 1-23. (In Chinese.)

Watanabe T. 1999. Irrigation water requirement. In Advanced Paddy Field Engineering, Mizutani M, Hasegawa S, Koga K, Goto A, Murty VVN (eds). The Japanese Society of Irrigation, Drainage and Reclamation Engineering: Tokyo; 388 pp.

Wen LJ. 1995. Paddy field, groundwater and land subsidence. Proceedings of the Sino-Japanese Workshop on Agricultural Engineering, Taipei, Taiwan; 29-56. 